\title{
EL PAPEL DE CEUTA EN LA POLÍTICA EXTERIOR DE JAIME II DE ARAGÓN
}

\author{
Rica AMRÁN-TEDGHI
}

\section{INTRODUCCIÓN}

Ceuta, conocida como "Abyla» bajo la dominación fenicia, fue la "Julia Trajecta» de los cartagineses; denominada "Septum» 0 "Septa» bajo los bizantinos, su nombre es transformado en el de «Sabta» (Cepta) tras la conquista árabe del año 711'.

Frontera natural entre musulmanes norteafricanos y aquellos que habitaron el alAndalus: los Omeyas de Córdoba intentaron tomarla pues comprendieron rápidamente que era la puerta para su expansión territorial en el norte de África. Hammudies, almohades, almorávides, hasáfidas y merinidas ${ }^{2}$, hasta llegar a la conquista portuguesa de la plaza en $1415^{3}$, pasaron por el gobierno local, todos por razones comunes,

1 SUREDA DE BLANES, F., Abyla Herculana, Madrid 1925, p. 55.

GLICK, T.F., Islamic and Christian Spain in the early Middle Ages, Princeston 1979, pp. 31-32.

2 AMRÁN, R., Ceuta y el mundo cristiano mediterráneo durante los siglos XII y XIII, Ceuta 1986, pp. 7-22.

- «Acercamiento a la historia económica de Ceuta, siglos XII y XIII", Actas del Congreso Internacional "El Estrecho» de Gibraltar, UNED, Madrid 1987, pp. 221-230.

3 AMRÁN, R., El norte de África como refugio de judíos y conversos según las crónicas de los reyes de Castilla, siglos XIV-XV, Hesperis (Université de Rabat), (en prensa).

- «Precedentes a la conquista portuguesa de Ceuta», Actes du Congrès International Bartolomeu Dias e sua época, Porto 1989, pp. 117-129.

- «Juifs et musulmans à Ceuta auX XVI-XVII èmes siècles", Communication du Colloque International organisé par le Centre Intenational de Recherche sur les Juifs du Maroc, octobre 1995 (en prensa).

- "La situación de los judíos en el norte de África según el "Libro de los veedores de Ceuta" y "The present state of the jews in the north Africa" ", Hommage à Haïm Vidal Sephiha, SEPHARDICA (ed. Peter Lang), Berlin 1996, pp. 435-443. 
de tipo político y económico, bien específicas: su posición estratégica, la capacidad de su puerto (uno de los mayores del norte de África, durante el periodo medieval), las riquezas marítimas de sus costas y por ser un punto de encuentro indiscutible en las rutas comerciales, para los diferentes países de esta época.

\section{CEUTA Y LAS POTENCIAS DEL OCCIDENTE MEDITERRÁNEO}

Si los diferentes pueblos musulmanes, peninsulares y norteafricanos, desearon una dominación política para llegar a monopolizar la economía de la ciudad, otros países estuvieron más interesados en poseer una hegemonía total o parcial del comercio con la plaza. Es el caso de Génova y Marsella.

Sabemos que las relaciones mercantiles entre cristianos y musulmanes, aunque existente desde antiguo fueron restringidas. La existencia de una lista de mercancías prohibidas son recogidas ya por el III concilio de Laterán, del año $1179^{4}$, y el sínodo de Montpellier de $1195^{5}$. Inocencio III, año 1215, en el IV concilio de Laterán, reforzó las medidas anteriormente adoptadas:

«Excommunicamus praeterea et anathematizamus illos falsos et impios christianos, qui contra ipsum Christum et populum Christianum sarracenis arma, ferrum et lignamina deferunt galearum; eos etiam quui galeas eis vendunt, vel naves, quique in piraticis sarracenorum navibus curam gubernationibus exercent, vel in machinis aut quibuslibet aliis aliquod eis impendunt concilium vel auxilium, in dispendium Terrae Sanctae, ipsarum rerum privatione mulctari et capientium servus fore cessemus...» ${ }^{6}$.

Estas medidas aunque fueron suavizadas bajo Honorio III, el 31 de octubre de 1224, de nuevo se renovaron, el 10 de agosto de este mismo año, con Gregorio X:

«ltem excommunicamus et anathematizamus illos qui equos, arma ferrum vel lignamina deferunt sarracenis, quibus christianos impugnant» ${ }^{7}$.

Sería Urbano IV quien daría un nuevo giro a las susodichas prohibiciones; el 23 de octubre de 1263 redactará su sentencia, repitiendo aquellas normas adoptadas en el IV concilio de Laterán:

4 «Ita quorundam animos occupavit saeve cupiditas ut cum gloriae nomino christiano sarracenis arma, ferrum et ligamina galearum dederant, et pares eis neccessaria suministrabant».

MANSI, I.D., Sacrorum conciliorum et amplissima collectio, reed. 1902, XXII, col. 230.

5 MANSI, XXI, col. 1160.

6 MANSI, XXII, col. 1066.

7 AUVRAY, L., Les registres de Gregorie IX (1239-1241), Paris 1906, no 332. 
«Ecommunicamus praetere et anatahematizamus illos falsos et impios christianos qui contra ipsum Chistum et populum christianum sarracenis arma, ferrum et lignamina deferunt galearum, eos etiam qui galeas eis vendunt...»8.

Tras periodos más o menos severos, sería Nicolás IV quien restablecería las antiguas prohibiciones; así leemos, el 23 de agosto de 1291 :

«... arma, ferrum, lignamina, victualia et alia quecumque mercimonia in Alexandiam vel alia loca serracenorum terra Egiptia ${ }^{9}$ deferre vel mittere seu de portubus eorum eisdem deferantur... ${ }^{10}$.

Clemente $\mathrm{V}$ siguió el camino emprendido por sus predecesores, al igual que aquellos que le sucedieron en la silla pontificia Juan XXII y Nicolás IV: dependiendo de la situación política del momento las normas relativas al comercio fueron más o menos severas.

Sobre esto Jaime Vicens Vives nos dice que el comercio con los países cristianos «fue un comercio de tipo normal», y continua: «en cambio el realizado con los musulmanes tuvo desde el principio una faceta especial: hasta cierto punto fue un comercio ilícito, de contrabando " ${ }^{11}$.

Los comerciantes al llegar a Ceuta, y a todo el norte de África, en general, debían abonar un impuesto, un $10 \%$ del valor real de la mercancía, en especia o en metáli$\mathrm{co}^{12}$ (a excepción de Génova, la más directa rival de la corona de Aragón, que pagaba un $8 \%^{13}$ ) al que se añadía un $1 \%$ destinado a pagar el gobierno local, denominado «intalaca».

Sin embargo lo más importante era salvaguardar la integridad física de los mercaderes y preservar sus productos de todo tipo de peligros. Para la buena marcha de las relaciones comerciales ceutíes se decidió:

1 Seguridad a los individuos que circulaban por la ciudad.

20 Responsabilidad de los cónsules sobre los diferentes fondacos ${ }^{14}$.

8 GUIRAUD, J., Les registres d'Urban IV, Paris 1901, no 468.

9 Enviada también a Génova.

LANGLOIS, E., Les registres de Nicolas $N$, Paris 1881, no 6784.

10 - Les registres de Nicolas $N, n^{\circ} 6784$.

11 VICENS VIVES, J., Historia económica de España, Barcelona 1959, p. 188.

12 MAS LATRIE, M.L., Traités de paix et de commerce divers concernant les relations des chretiens avec les arabes de l'Afrique septentrionale au Moyen Ages, Paris 1866, vol. I, p. 204.

MERCIER, E., Histoire de l'Afrique septentrionale, Paris 1888, II, p. 210.

13 «... ut per omnes terras Moadebeant ire; et in aliqua terra ipsorum nisi de centum octo nullam dare debeant conductionem, except Buzee, ubi decimum debent, quia quartum ipsius decimi debet reverti ad commune Janue,...».

MAS LATRIE, II, p. 108.

14 Tenemos conocimientos de la existencia de dos grandes en la plaza: el de los genoveses y marselleses y el de los súbditos de la corona de Aragón. 


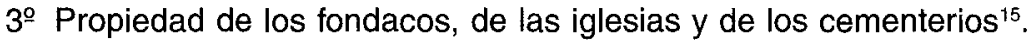

$4^{9}$ Responsabilidad civil personal, en el caso de robo o asesinato a un súbdito musulmán ${ }^{16}$.

$5^{\circ}$ Libertad religiosa ${ }^{17}$.

$6^{0}$ Prohibición de la piratería ${ }^{18}$.

$7^{9}$ Anulación de la antigua costumbre, por la cual se atribuía los restos de un naufragio a aquellos que los encontraban ${ }^{19}$.

Los principales productos que las distintas potencias adquirían en Ceuta eran:

a) Compraban: hierro ${ }^{20}$, pieles $^{21}$, sal ${ }^{22}$, corales ${ }^{23}$, pinturas $^{24}$, azúcar ${ }^{25}$, cera $^{26}$, esclavos ${ }^{27}$, aceite ${ }^{28}$, algodón ${ }^{29}$, etc.

b) Vendían en Ceuta: vino ${ }^{30}$, harina ${ }^{31}$, telas $^{32}$, sedas $^{33}$, $\operatorname{armas}^{34}$, esclavos ${ }^{35}, \ldots$

15 MAS LATRIE, I, pp. 89-90.

16 MAS LATRIE, I, pp. 90-93.

17 MAS LATRIE, I, pp. 104-105.

18 MAS LATRIE, I, pp. 94-96.

19 Comisión Histórica de las campañas de Marruecos, Acción de España en África, Madrid 1935, I, p. 200.

20 VICENS VIVES, p. 196.

21 MAS LATRIE, I, p. 296.

22 MAS LATRIE, I, p. 217.

GAUL, M., "Para un mapa de la sal hispana en la Edad Media», Homenaje a J. Vicens Vives, I, (1961), pp. 483-497.

23 HEYD, W., Histoire du commerce du Levant au Moyen Ages, Leipzing 1923, 1, pp. 609-610.

24 MAS LATRIE, I, p. 210.

25 MAS LATRIE, I, p. 218.

26 MAS LATRIE, I, p. 218.

27 MAS LATRIE, I, p. 215.

28 Vicens Vives, p. 195.

MAS LATRIE, I, p. 218.

29 VICENS VIVES, p. 196.

30 BLANCARD, L., Documents inedits sur le commerce de Marseille au Moyen Ages, Marsella 1885, I, pp. 72-73.

PERNOUD, R., Histoire du commerce de Marseille, Paris 1949, p. 176.

MAS LATRIE, I, pp. 212-214.

31 Con respecto a Marsella ver: BLANCARD, L., I, p. 90.

32 MAS LATRIE, I, p. 211.

33 LÓPEZ, R.S., The Trade of Medieval Europe, Cambridge Economic History, VII (1950), pp. 257 354.

34 MAS LATRIE, I, p. 210.

35 Referente a Marsella, ver: PERNOUD, R., I, p. 177. 


\section{LA CORONA DE ARAGÓN Y CEUTA}

\section{Economía}

Podemos considerar que el apogeo catalano-aragonés comenzó en el siglo XI, y que continuaría hasta el año 1330. En 1291, tras firmarse el acuerdo de Monteagudo entre Castilla y Aragón, quedó determinada como zona de influencia de esta última el este del río Mulaya. Bajo ella estaría el Magreb, es decir la zona occidental a la cual se denominó Ifrikiya ${ }^{36}$.

Es a partir de entonces cuando los catalanes intentaron, con mayor ímpetu, tomar la plaza de Ceuta, con la que desde 1227 habian soñado. Las razones de la corona eran claras: la ciudad era la puerta que les abriría las rutas atlánticas, a la vez que paso obligado hacia las del norte de África.

$Y$ es en este punto que vemos reflejado los intereses aragoneses, y que les diferencia del resto de las potencias que llegan a negociar en Ceuta: la conquista física era condición «sine qua non» se podía llegar a crear un área de expansión comercial. Esta ambición se vio truncada solamente en 1415, cuando la plaza es conquistada por los portugueses.

A otros niveles económicos, su agricultura e industria llevaron a la corona de Aragón a ser una de las más ricas y productivas de la Península lbérica, y de ahí su éxito en las rutas comerciales del norte de África: trabajaban la piel, con la que fabricaban desde pergaminos a cinturones, zapatos, y todo tipo de marroquinería en general. En el campo textil se destacaron en la producción de telares, en materia como lino y algodón; tras la conquista de Sicilia en 1282, el desarrollo de la industria textil se hizo de mayor envergadura, y en el que a partir de esos momentos se fabricaron desde los telares más refinados y lujosos hasta los más económicos, aunque de una excelente calidad. La artesanía también fue importante durante estos siglos: vajillas (desde las más corrientes a las delicadas de tradición árabe), cerámicas, etc. A pesar de todo, y por lo cual se hizo famosa sería la industria naval, conocida en todo el mediterráneo como una de las de mayor importancia.

Como vemos por lo brevemente expuesto, la rica producción local llevó a desarrollar mercados locales y a buscar otros en ultramar. Las exportaciones a países peninsulares y de la Europa cristiana eran frecuentes: Castilla, Navarra o Francia, son alguno de los ejemplos. Pero las miras de la corona estuvieron puestas en los países musulmanes con los cuales las posibilidades comerciales creían más provechosas, aunque las sanciones, citadas anteriormente, dificultaron este.

36 Ver especialmente: DUFOURQ, Ch.E., L'Espagne catalane et le Magrib au XIlth et XIV siècles, Paris 1966.

LALINDE ABADÍA, J., La corona de Aragón en el mediterráneo medieval (1229-1497), Zaragoza 1979.

VICENS VIVES, J., pp. 187-194.

VILAR, P., El declive catalán en la baja Edad Media. Hipótesis sobre su economía. Crecimiento y Desarrollo, Barcelona 1964, pp. 325-430. 
Tenemos conocimientos que los principales productos con los cuales negociaron los súbditos de la corona de Aragón en el norte de África y muy especialmente en Ceuta fueron:

a) Exportaron: trigo ${ }^{37}$, vino ${ }^{38}$, frutos $\operatorname{secos}^{39}$, miel $^{40}$, lana ${ }^{41}$, cerámicas ${ }^{42}$, esclavos ${ }^{43}$, telas ${ }^{44}$, etc.

b) Importaban: aceite ${ }^{45}$, algodón ${ }^{46}$, hierro ${ }^{47}$, pieles $^{48}, \ldots$

Como vemos hay un mayor número de productos exportados que importados, y de ahí su interés por llegar a la susodicha ciudad.

\section{Política de la corona de Aragón ${ }^{49}$}

T.N. Bisson ${ }^{50}$ define de esta manera a Jaime II: «Si su abuelo (de Jaime II) fue un gran conquistador, y su padre el mayor defensor de la dinastía, Jaime II fue el mejor gobernador (de la corona de Aragón)». Para reafirmar esta idea traemos las dos cartas siguientes relacionadas con la plaza.

Como ejemplo de esta política traemos a estas páginas dos textos relativos a la política de Jaime II en el norte de África, y más particularmente en relación con la plaza de Ceuta.

El primero de ellos fue redactado en Barcelona el 3 de mayo de 1309 por Jaime II, y dirigido a Abou-Rebia Soliman ${ }^{51}$, rey de Marruecos, anunciándole las condiciones para ayudarle a continuar con el sitio de Ceuta, ocupada por aquel entonces por el rey de Granada, ayudado por Génova. Se adjunta también una serie de instrucciones al

37 Tortosa tenía el monopolio en el río Ebro.

38 MAS LATRIE, I, p. 213; VICENS VIVES, p. 195.

39 VICENS VIVES, p. 195.

40 VICENS VIVES, p. 195.

41 VICENS VIVES, p. 195.

VISKO, Ch.J., «El castellano hombre de llanura. La exportación ganadera en el área fronteriza de la Mancha y Extremadura durante la Edad Media», Homenaje a J. Vicens Vives, I (1965), pp. 201-216.

42 VICENS VIVES, p. 196.

43 VICENS VIVES, pp. 196-198.

LÓPEZ, R.S., The Trade, pp. 261-262.

44 VICENS VIVES, p. 195.

45 VICENS VIVES, p. 195.

46 VICENS VIVES, p. 196.

47 VICENS VIVES, p. 196

48 MAS LATRIE, I, p. 216.

49 BISSON, Th.N., Conservation of coinage, Monetary Explotations and its Restrain in France, Catalonian and Aragon (1000-1225), Oxford 1979, pp. 64-106.

O'CALLAGHAN, J.F., A History of Medieval Spain, London 1975 (especialmente el capítulo denominado «The oversas expansion of the Crown of Aragon», pp. 382-406).

50 BISSON, Th.N., The Medieval Crown of Aragon. A short history, Oxford 1986, pp. 72-173.

51 MAS LATRIE, I, p. 297. 
vizconde de Castelnou, para que este explique a Abou-Rebia el por qué no le había ayudado a atacar con anterioridad la ciudad de Ceuta (en esos momentos en manos del señor de Granada), hasta no haber obtenido el compromiso del rey de Castilla, atado como estaba al último tratado sellado con él, siendo el rey de Granada vasallo del castellano. A través de este texto vemos reconstruida la historia de la corona de Aragón: a la muerte de Pedro III le sucedió su hijo Alfonso III (1285-1291), quien muere repentinamente, pasando el trono entonces a su hermano Jaime II, heredero de Sicilia. Sancho IV el bravo, al que se alió para hacerse con la corona, sin resultado, pues en 1294 rompió su pacto. Sería renovado sólo en la persona de su hijo Fernando IV (1295-1312), con el cual Jaime II llegó a un acuerdo de actuar contra el rey de Granada, aunque todos los derechos de conquista los cedió al castellano, en diciembre de 1308. Como vemos, pocos meses más tarde se decidiría a actuar y ayudar, como había sido la costumbre entre los monarcas del trono aragonés, a los soberanos de Marruecos ${ }^{52}$.

Por el presente acuerdo el aragonés se aliará, a favor o contra, todo «amigo o enemigo» de Abou-Rebia Soliman, y le alquilará a este cada una de las galeras aragoneses por 2.000 doblas cada cuatro meses (pasado estos, pagará sólo 1.000 doblas de cuatro en cuatro meses). Aborrabé deberá dar sueldo a 1.000 caballeros para mantener la guerra contra Ceuta, y a la conquista de estas los bienes muebles serán para Jaime II.

«Al muy alto, è muy noble, è muy poderoso rey, Aborrabe, miramomelin de Mar-/ruecos, don Jayme, por la gracia de Dios rey de Aragon, de Valencia, de Serdenya,/ de Corsega, cuende de Barcelona è de la santa eglesia de Roma senyalero, almirantel è capitan general, saludes muchas como á rey que mucho amamos de coraçon, è cob-/diciamos que Dios dé mucha de honra, è de buenaventura, è de victoria, contra todos/sus enemigos, è quel lexe complir el su deseo è el su plaçer./

Rey noble, façemos vos saber que sobre los fechos tractados entre vuestro hermano,/el rey botebet, á qui fue mandadero Bernardo Seguin, amado nuestro, con/noes de los quales vos sedes certificado, segunt nos envio decir el dicho Bernardo/Seguin, è vos place que vengan á buen acabamiento,

52 Abu Yusuf, rey de Marruecos pidió ayuda a Jaime I el conquistador en 1274, para conquistar Ceuta.Quería asediarla por mar, y para ello necesitaba barcos, los cuales poseía el aragonés:

"Manifiesta cosa sia a tots com Nos aben Yusuf Miarammollin Senyor de Marrochs e Feza e Suyamoza, e de ses pertenencias, Senyor dels Benimarins... ab vos noble en Jaume, per la gracia de Deu Rey D'Arago, è de Malloques, è de Valencia, Comte de Barcelona...

E puis que romanga aquella pau entrels votre fills è los nostres, en tal manera que Vos nos façats ayuda à pendre Cepta, è que nos enviets deu naus armades è deu galees,...».

MAS LATRIE, I, p. 285.

Nos aporta luces sobre el tema el trabajo de:

GASPAR REMIRO, M., El negocio de Ceuta entre Jaime II de Aragón y Aburrebia, sultán de Fez, contra Mohamed III de Granada, Madrid 1925. 
enviamos á vos, el noble è muy/ honrado è amado consellero nuestro, don Jaçpert viçconde de castelnou;el qual vos/enviamos con pleno poder de tractar è ordenar è firmar todas cosas que nos podiamos facer, como á aquel en quien mucho fiamos, è es çertificado de todo nuestro entendi-/miento, porque vos rogamos, rey, que lo creades de quantovos dira de parte nuestra./E porque nos entendiemos por el dicho Bernardo Seguin que vos queriades saber de/nos è por nuestra carta quales eran aquellas cosas que eran tractadas, è las quales/ nos demandavamos ques complissen, mandamos las poner è escribir en esta carta /nuestra, segunt se siguen./

1. Tractado es que los reyes sean amigo de amigo è enemigo de enemigo, contra/ todos los reyes del mundo de los Moros./

2. Item, que el rey Aborrabe dara cascuna galea con todo su complimiento è/ armada para quatro meses, dos mil doblas./

3. Item, pasados acquestos quatro meses primeros, dara mil doblas por galea, de/ quatro en quatro meses, mientras menester las aura./

4. Item, el dito rey Aborrabe dara sueldo para mil cavalleros, para mantener la/ guerra, entro á tanto que aya acabado su entendimiento de Cepta./

5. Item, prometra è jurara en su ley que no aura paç ni tregua nunca con el rey /de Granada, sin voluntad del rey de Aragon./

6. Item, quando sea presa Cepta, todo el mueble sea del rey d'Aragon, è las/ personas è el lugar sean del rey Aborrabe./

Dada en Barcelona, tres dias andados del mes de Mayo, en e, anyo de Nuestro/ Senyor, de mil trescientos y nueve.-Bernadus de Aversone, mandato regio./

\section{II}

Primerament, lo saludara de part del dit rey d'Arago.

En apres, il recomptara la gran amor è bona voluntat que fo el temps passat entre/la casa de Marrochs è lacasa del dit rey d'Arago, 'e especialment en temps de son avi, / el rey Abenjacob.Apres la mort del quel rey Abeniacob, lo rey Botebet, volent rego-/nescer è refrescar la bona amor que avia ahuda son avi ab lo rey d'Arago, trames sos/missatges al dit rey d'Arago, ço es, en Bernat Segui è ell veyll Abulabez fill de Gau-/ramet, qui requeséren lo dit rey d'arago, de part del dit rey Botebet, que li plagues/que fos aquella amor entre ells, qual era estada entre son avi e ell;encara pregaren,/ è demanaren que li plagues donar ajuda contra el rey de Granada, senialament de/galees per cobrar Cepta del dit rey, qui la li tenia forçada, de la qual cosa allse tenia/fort per minuat, que tant vill rey com aquell fees á ell força;encara retrasqueren los/dits missatges al dit rey d'Arago, que gran vergonya li era tant vill hom con aquell/ tengues terra prop de tant noble rey com ell, è en sa presencia.

Apres recomptada la missatgeria, compliment è sabia per los dits missatges del/ rey Botebet, lo rey d'Arago respos, que ver era que tots temps era estaba bona amor è/pau entre la casa de Marrochs è la sua, è 
senyaladament en temp's del rey Abenjacob,/de qui el dit rey d'Arago havia membrança, è que li plahia molt que aquella fos man-/ tenguda entre ells tots temps, á que era apparellat de fer en sos fets tot ço que ell/ pogues, axi com per amic leyal, guardant pero sa fe è sa leyaltat, la qual tots temps/ guardaren sos predecessors á tots sos amics. E aço deya per la amor è la convinença /que era entre ell è el rey de Castella, la qual era aytal que el rey de Castella, el temps/ que fou pau ab lo dit rey d'Arago, lo reques el prega que volgues quel rey de Granadal fos en aquella pau, axi com a vassayl del dit rey de Castella;è el rey d'Arago otorga / ho, per honor del dit rey de Castella.

$\grave{E}$ axi, per aquesta raho, el rey d'aragono podla otorgar la ajuda quels dits missatges/ demanaven contra el rey de Granada, mas que el dit senyor rey d'Arago, per amor è/ per honor del dit rey Botebet, è per que pogues satisfer á voluntat, è per lo retreyt/ que li fayen los missatges de part del rey Botebet, se trebayleria de tractar è procurar/ ab lo rey de Castella quel solves d'aquella covinença.Per la qual cosa, lo dit rey/ d'Arago trames encontinent un dels maiors de son conseyl al rey de Castella.

E feta aquesta resposta, fo fet alcun tractament de la ajuda que demanavan los dits/ missatges de part del rey Botebet, è de co que aquell rey Botebet degues fer al dit rey/ d'Arago, del qual s'en porta un ecrit en Bernat Segui, è romas ne altre en poder del/ dit rey d'Arago. $\grave{E}$ apres d'aço, patiren s'en los dits missatges;è á pochs dies ans que/ s'en fossen tornats, agueren ardir cert quel dit Botebet era mort, è que era rey/ Aborrabe. ̇̇ jaç sia quel dit rey d'Arago agues despagament de la mort del dit rey, pero hac gran pagament quan ohi que era rey Aborrabe, qui era son frare, è nebot' d'aquell mateix rey Abenjacob, amic seu.

En apres, en Bernat Segui ab l'altre companyo seu, axi con aquell qui volia recaptar/ ço per que era vengunt, torna, è dix al dit rey d'Arago si li plahia que el pogues dir/ aquella bona resposta á son senyor el rey Aborrabe, que el sabia per cert que á ell/ plauria aço mateix que plahia al rey Botebet.

$\dot{E}$ el senyor rey respos li que li plahia/ molt que lui pogues dir secretament, è que ell è el rey de Castella se devie veureensemps dins breus dies, è que faria tot son poder que pogues fer la ajuda complidament/ quel rey Aborrabe hauria ops d'ell.

$\dot{E}$ apres d'aço, lo dit rey d'Arago è el rey de Castella hagueren vistes; en aquell/ temps, vench en Pere Marti d'Orta al dit rey, ab la carta del dit rei Aborrabe, per la/ qual se mostrava que al rey Aborrabe plahia esser en amor è en convinença ab lo dit/ senyor rey;è aporta aytambe carta d'en Bernat Segui, en la qual se contenia clara-/ment que el rey Aborrabe vulia è li plahia molt que ço que era tractat entrel dit senyor/ rey è el rey Botebet fos entre ells, è vengues à compliment. Per la qual cosa, lo rey d'Arago fermant se en la carta del dit rey Aborrabe, è en ço quel dit en Bernat Segui/ li trames á dir, se trebaylla molt fortament que acabas ab lo rey de Castella qu'el/ solves 
d'aquella covinença, è no tant solament acaba aço, mas/ encara qu'el dit rey de Castella mateix fees guerra al rey de Granada la qual començal á pochs dies./

E tantost, lo rey d'Arago d'amunt dit, veent que les galees nos' podien fer dins pocs/ dies, ne l'aparallament que y fa mester, mana fer gran quantitat de galees, per complir/ ço quel rey Aborrabe demanava, è que les pogues haver tant tost com los tractamens/ fossen endressats. Evvolch lo dit rey d'Arago que un conseller seu, don Gonçalvo/ Garcia, ab qui havia tractat d'aquests fets en Bernat Segui, trameses un missatge al/ dit en Bernat Segui, que procuras quel tractament vengues á acabament de part del/ rey Aborrabe, que de la parte de ça tot era endreçatè acabat./

Lo qual missatge fo á en Bernat Segui, è ell respos al dit rey d'Arago è al dit con-/seller seu que el rey Aborrabe, è tots aquells de son conseyl, havien ahut gran plaer/ d'aquelles noves com les ahiren, è qua plahia molt al rey Aborrabe que aquests trae-/tamens venguessen á compliment, è que era apparellant è volenteros de complir e/ guardar totes aquelles coses que fermades serien entre ell è el dit rey d'Arago, è que/ guardaria encara mellor la amor è les convinences que no havien fet negun de sos pre-/decessors, perço com una vegada son avi lo rey Aben jacob se empres ab los Crestians/ contra los Andaluços, è puys desempara los Crestians 'fo ab los Andaluços;è que el no ho entenia á fer axi que abans hauria pau ab Jueus, que Deus confona! que no/ hauria ab los Andaluços. È perço demanava è vulia lo dit rey Aborrabe qu'el senyor/ rey d'Arago Ii trameses un hom honrat de son conseyl, ab/plen poder de tractar è/ fermar sobre los tractaments d'amunt dits, los quals lo dit rey dÀrago li feés saber/ per sa carta declaradament./

$\dot{E}$ sobre aço, vench ab volentat del dit rey Aborrabe en Ramon Torro, parent d'en Bernat Segui. È tantost, lo senyor rey trames un cavaller de son conseyl, ab una/ galea lo qual ha nom Artal Daçlor,al dit rey Aborrabe, 10 qual anant son cami, fe a Cartagenia, hon hac ardit que avia galees del rey de Granada en mar, è no hac d'acort que passas á abant;ans trames lo dit Ramon Torro á en Bernat Segui ab una/ barcha, è perço, car no poch passar, tornasen al dit rey d'Arago./

De la qual cosa, lo senyor rey com la ohi fo molt despagat, è amntinent ordona que/ fossen armades galees è leyns tro á setse, les quals trames contra la dita armada del/ rey de Granada;è ordena aytambe qu'el noble en Jacpert vescomte de Castennou anas/ per missatge ab les dites galees al dit rey Aborrabe perço que pus segurament, è pus/ honrada, pogues anar, è encara que les galees anassen contra Cepta en serven del dit/ rey Aborrabe, è que destrenguessen Cepta que socors de gents ne de vianda ne y/pogues entrar;è entretant los dit rey dÀrago fo apparellar major quantitat de galees./

E mana encara al dit noble en Ja'pert, que fos dàvant lo rey Aborrabe per trer á / compliment los tractamens d'amunt dits, è donali plen poder de fer totes aquelles/ coses, è tractar 'fermar, quel dit rey d'Arago podria fer.' 
È axi requira è deman al dit rey Aborrabe que ell complescha è ferm è fassa complir/ los tractaments d'amunt dits, pus lo dit rey d'Arago, quant á la sua part es, ha/ començat á fer ço que ops era è es á aquests fets./

Item, parria raho que, pus lo senyor rey mou la guerra per lo rey de Marrochs, è li ajuda á destruir sos enemichs, que com el haura acabat son enteniment de Cepta, ço/ que sera tost, quel dit rey ajut al rey d'Arago de galees è de moneda á fer la guerra all rey de Granada;è aço comena el senyor rey á en Jacpert;mas pero finalment, que/ per aquest capitol no romangues./ $/ x^{53}$.

La segunda carta, $1^{\circ}$ de mayo de 1323 , de Jaime II a Abou-Said-Othman, rey de Marruecos, podemos divisar en ella tres partes bien definidas:

1. Reclamación por parte del aragonés de ciertos compromisos que el anterior rey de Marruecos, Abu Said, había incumplido, en relación con lo acordado a la toma de Ceuta (de manos del rey de Granada).

2. Pedía un préstamo de dinero y hombres (caballeros aragoneses, que les servían en Marruecos), necesario en esos momentos a Jaime II por la guerra que se produjo en Cerdeña y Córcega.

3. Renovar los acuerdos de paz y de comercio.

"Al molt alt, è molt noble, è molt poderos, Buçayt, rey de Marrochs è del Garb, en/ Jacme, per la gracia de Deu, rey d'Arago, de Valencia, de Sardenya è de Corsega,/ è compte de Barchelona, è de la santa egleya de Roma senyaler, almiral è capitan/ general, salut, axi com á rey per á qui volriem honor è bonaventura./

Rey, fem vos saber que, per alguns afers, trametem á la vostra presencia l'amat è/ feel nostre en a Romeu de Corbera, conseller è de casa nostra, que aquesta carta vos/ part nostra. On rey, vos pregam que vos lo dit missatge nostre vullats benignament/ reebre, è ohir, è creure á ell firmament, è sens tot dupte de tot ço queus dira per/ part nostra, è grahir vos ho hem molt./

Dada en Barcelona, primer dia del mes de Maig, en l'any de Nostre Senyor mil/ trescents vint è tres -Bernardus de Aversone, mandato regio./

\section{II}

1 Primerament, salut de part del senyor rey d'Arago lo dit rey de Marrochs, ab/ cuvinents paraules, è digili de son bon estament, è demanli del seu./ 2 En apres, deja continuar se missatgeria en aquesta forma: dient/i que certa/ cosa es que entre les cases lurs, d'Arago è de Marrochs, ha estada en temps passad/ entrels predecessors dels dits reys, è encara entrel dit senyor rey d"Arago, amor è/ amistat bona, è convinençes de pau è de ajuda de la una

53 MAS LATRIE, I, pp. 297-298. 
casa á la altra;è senyalada-/ ment foaren acquestes coses entrel dit senyor rey d'Arago è el rey Aborrabe, en tant/ encara quel senyor rey d'Arago qui havia pau ab lo rey de Granada, qui lavors era/ li volch esser enemich è s'empres contra ell per lo dit rey Aborrabe, è feu ajuda á el/ contral dit rey de Granada, qui li tenia forçada Cepta, de galees en gran quantitat;/ hi trames en elles lo noble ça en rera en Jaçpert, veçcomte de castellnou, quin fo/ davant lo dit rey Aborrabe, è puys ab les galees fo el fet de Cepta, com fo cobrada ál la senyora del dit Aborrabe.E jassia que de part del dit rey Aborrabe fossen al dit/ rey d'Arago atorgades alcunes coses, aixi de ajuda de sou de cavallers, per mantenir/ la guerra del dit rey de Granada, è de pagar de galees, com del moble de Cepta,/empero no fo cumplit, è el dit rey Aborrabe hac son enteniment de Cepta;ne encara/ de ço que per acquesta raho fo assignat sobrel dret dels mercaderss qui venen á la terra/ del dit rey de Marrochs, non fo res pagat ni satisfet al dit rey d'Arago./

$3 \dot{E}$ com ara lo dit senyor rey d'Arago, segons que creu que ha entes lo dit rey/ de Marrochs, haia grans fets è fort senyalats á gran honor sua è de son regne, per/ acquesta del regne seu de Sardenya è de Corsega, per raho de la qual con-/ questa, segons que ell pot be pensar, li ha convengut è li cove á fer molt grans messions/ è despeses;perço lo dit senyor rey, esguardant la bona amor è amistat que ha estat è / sera, Deu volent, entre les cases d'Arago è de Marrochs, è confiant que en aytal è/ tant assenyalant fet, lo dit rey de Marrochs li sera bon amich è li ajudara, ha volgut trametre é ell en Romeu de Corbera. 4 Per quelprega que ell, esguardant les coses d'amunt dites, è specialment com/ lo dit senyor rey d'Arago ha ajudat, è es appereylat de ajudar á ell è á la sua casa,/en semblant cas è en major, que vula è li placia de accorrerli d'aquella quantitat de/ moneda que pertanga al dit rey de Marrochs, è que sia de pendreal dit rey d'Arago,/ è ell grahir lin ha molt;è en aço, lo dit rey de Marrochs li dara á conexer la bona/voluntat è la amor que li ha, è el rey d'Arago faria per ell, en semblant cas, è en/ maior, ço que fos honor sua è be de son regne./

$5 \dot{E}$ sil dit rey de Marrochs atorga que ajudara al dit senyor d'Arago, mas que vol/ saber de quina quantitat seria pagat lo rey d'Arago, diga lo dit en Romeu que be pot/ pensar lo dit rey de Marrochs quina ajuda se pertany á aytal rey com ell es, de fer/ á aytal princep com es lo rey d'Arago, è en tan grans affers, è aixi que ell hi faça/ segons qu'el senyor rey d'Arago espera è confia d'ell.E si ell volia qu'el dit missatge/ expressas la quantitat de que enten 10 dit senyor rey d'Arago, pot dir que semblaria/ que elmenys degues esser la dita ajuda de quaranta mille dobles d'or;è sobre aço faça/ sa puja de obtenir è haver aquella maior quantitat que puga.E finalment, si als no/ podia, quen preses tro á quantitat de deu mille dobles./

6 Si lo dit rey de Marrochs, per aventura, demanara que pus ell fa la dita ajuda,/ que en vol que totes les coses d'amunt dites, è ço que pugues esser demanat per les/ dites covinençes, li sien diffinides è absoltes, respona lo missatge queu fara volenter, è qu'en ha poder./ 
7 Encara, sil dit rey de Marrochs demanara è volra que pau è amistat sia reno-/ vellada, è convinences fetes entrel senyor rey d'Arago è ell, diga lo dit Reomue quel/ senyor rey d'Arago, si ell li es bon amich en aquesta ajuda, es aperellat de donar hi loch/tota hora que á ell placia. $\dot{E}$ si li demanaven ell si ha poder sobre aço, respondera que/ hoc, è, ab que la ajuda sia covinent, ell la fermar de part del rey d'Arago. Ė en aquell/ cas, mostras la carta del poder que s'en porta;è la forma de la pau fos aytal qual se / conte en la forma del procuratori./

8 Item, dira al dit rey de Marrochs que com alcuns cavallers naturals del dit rey/ d'Arago, qui son en son serviy, entena lo dit senyor rey haver en son serviy, en aquest/ fet de la conquest de Sardenya, pregalo que li placia de donar llicencia á ells que/ puguen venir al serviy del dit rey d'Arago, aquells, ço es á saber quel missatge li/ nomenara. Ė d'açol' prega, per lo prechs que ja li ha fetsab carta sua, que li tramete/ en Jacme Segui, ab cent homensá cavayl á la genetia./

9 Item, si demanen ajuda de galees, puga ho prometre, lo rey de Marrochs donant/ per cascuna galea, ab tot son compliment è armada, per quetre meses, tres mille/ dobles d'or; è passats los quatre meses primers, que do dos mil dobles d'or per galea/ de quatre meses, mentre mester les haura./, ${ }^{54}$.

El punto de vista más interesante, a nuestro parecer es el segundo, en el que se nos habla de las milicias cristianas aragonesas, al servicio del rey de Marruecos.

Dos elementos que influyen enormemente en la sociedad son el comercio y la guerra, y cuando estos se combinan, como en el caso presente, muchísimo mejor; estas milicias, modernamente las llamaríamos grupos de «mercenarios».

Desde un punto de vista militar los ejércitos cristianos eran más fuertes, sólidos y pesados, que las tropas musulmanas, caracterizadas por una mayor agilidad y movilidad. Los dos tipos de ejército, juntos podrían llegar a formar uno perfecto ${ }^{55}$. Y de ahí la presencia de pequeños grupos de musulmanes en las tropas cristianas (cosa no muy frecuente), y de caballeros cristianos, en los musulmanes, especialmente del norte de África.

La razón por la que los soldados cristianos llegan a África es por destierro de sus países natales respectivos: lo único que sabían hacer para ganar su sustento era guerrear y esto fue a lo que se dedicaron. La organización interna no demandaba grandes condiciones, aceptando a todo individuo que portaba caballo y armas; cada grupo poseía un "alcaide" ", el cual los dirigía. Países como Génova y Pisa alquilaban sus ejércitos de mercenarios al mejor postor; las coronas peninsulares, por el contrario,

54 MAS LATRIE, I, pp. 315-317.

55 GIMÉNEZ SOLER, A., "Caballeros cristianos en África y africanos en España», Revue Hispanique, XII (1905), pp. 299-372; XVI (1907), pp. 56-59.

AMRÁN, R., Ceuta y el mundo cristiano, pp. 21-22.

56 Bernardo Segui era el «alcaide» de las milicias aragonesas, que citamos en la primera de las cartas aportados en estas páginas. 
quizás por la situación de guerra latente, no lo hicieron. Podemos considerar la llegada de estos "caballeros hispanos" como una especie de emigración individual.

El otro dato abordado en este segundo punto es la guerra por la toma de Cerdeña y Córcega, las cuales les habían sido prometidas a Jaime II tras su renuncia a Sicilia. Los problemas internos de la corona y la guerra contra los musulmanes habían pospuesto veinte años su posesión, dominadas por los pisanos.

En junio de 1323 sale de puerto la flota aragonesa dirigidas por el hijo del rey de Portugal, Alfonso (el futuro Alfonso IV, 1325-1357, enemistado con su padre); en 1325 los pisanos habían sido expulsados de la isla ${ }^{57}$.

El establecimiento del gobierno aragonés en Cerdeña inicia una larga guerra comercial en el occidente mediterráneo entre ellos y Génova; estos últimos hasta el momento había mantenido en estos lugares su supremacía.

Queremos acordar que esta «lucha» ya había sido iniciado, aunque de forma más discreta en el norte de África, cuando genoveses y aragoneses intentaron monopolizar el comercio de la ciudad entre los siglos XII y XIII ${ }^{58}$.

\section{CONCLUSIONES}

Los dos textos presentados nos demuestran:

1. La importancia del norte de África, y más especialmente de Ceuta en los planes económicos de Jaime II. Es el primer eslabón para la extensión comercial en la zona.

2. El interés de la corona por poseer el monopolio comercial de la ciudad.

3. Que la crisis suscitada entre Génova y Aragón tras la conquista de Cerdeña, ya había tenido sus antecedentes en épocas anteriores, y en relación a la ciudad de Ceuta, causa de su antigua rivalidad por ostentar un dominio en el plano económico de la plaza.

57 O'CALLAGHAN, pp. 406-407.

58 Ver:

AMRÁN, R., Ceuta y el mundo cristiano, pp. 9-12, pp. 23-27.

-, "Acercamiento a la historia económica de Ceuta, siglos XII y XIII", Actas del Congreso International, El Estrecho de Gibraltar, UNED, pp. 221-230.

- "Un documento sobre el comercio realizado por judios en la ciudad de Ceuta", Estudios de Historia Medieval, Universidad de Valladolid, Valladolid 1991, pp. 25-28. 